\title{
Hot topic: Pathway confirmed for the transmission of melamine from feed to cow's milk
}

\author{
C. W. Cruywagen,${ }^{* 1}$ M. A. Stander, $†$ M. Adonis, $†$ and T. Calitz \\ ${ }^{*}$ Department of Animal Sciences, and \\ †Central Analytical Facility, Stellenbosch University, Stellenbosch 7602, South Africa
}

\begin{abstract}
Eight lactating Holstein cows were randomly allotted to 2 groups in a trial to establish whether a pathway exists for the transmission of melamine from feed to milk. All cows received oat hay ad libitum and $15 \mathrm{~kg}$ of concentrate pellets per cow daily. The concentrate pellets contained either melamine-contaminated corn gluten meal of Chinese origin (melamine treatment) or locally produced melamine-free corn gluten meal (control treatment). Cows in the melamine treatment ingested $17.1 \mathrm{~g}$ of melamine per day. Cows were milked twice daily, and milk samples were taken once daily during the afternoon milking for melamine and milk component analyses. Melamine appeared in the milk within $8 \mathrm{~h}$ after first ingestion of the melamine containing pellets. Melamine concentration reached a maximum of $15.7 \mathrm{mg} / \mathrm{kg}$ within $56 \mathrm{~h}$ after first ingestion, with an excretion efficiency of approximately $2 \%$. Milk solids and milk urea nitrogen were not affected by treatment. The melamine concentration dropped rapidly after changing all cows back to the control pellets, but melamine only declined to undetectable levels in the milk more than $6 \mathrm{~d}(152 \mathrm{~h})$ after last ingestion of melamine. Results from the current trial are important to the feed and dairy industries because, until now, any melamine found in milk and milk products was attributed only to the deliberate external addition of melamine to these products, not to adulterated ingredients in animal feeds.
\end{abstract}

Key words: melamine, feed, milk, corn gluten meal

Melamine $\left(\mathrm{C}_{3} \mathrm{H}_{6} \mathrm{~N}_{6}\right)$, or 1,3,5-triazine-2,4,6-triamine, is an industrial chemical that contains $670 \mathrm{~g} / \mathrm{kg}$ of $\mathrm{N}$ on a molecular weight basis (Merck, 2001). Because the $\mathrm{CP}$ contents of feeds and foods are calculated from their N content (AOAC, 2000), melamine can artificially increase the apparent protein content when added to feed and food ingredients. Chinese authorities have recently confirmed that 6 babies had died and 296,000

Received January 27, 2009.

Accepted March 8, 2009.

${ }^{1}$ Corresponding author: cwc@sun.ac.za had fallen ill in 2008 from drinking melamine-tainted infant formula (AllAboutFeed, 2009). Melamine, which was intentionally added to gluten meal, was also the cause of numerous pet deaths around the world in 2007 (World Health Organization, 2008a). Documented research results pertaining to melamine in production animal diets are limited. Clark (1966) reported that an intake of $>10 \mathrm{~g} / \mathrm{d}$ resulted in crystalluria and consequent death in sheep, whereas $7 \mathrm{~g} / \mathrm{d}$ fed to sheep with an average weight of $35 \mathrm{~kg}$ had no adverse effects. MacKenzie (1966) also reported weight loss and mortalities when melamine was fed to sheep. Although Newton and Utley (1978) showed that melamine is not an efficient $\mathrm{N}$ source for ruminants, they reported that a melamine intake of $45 \mathrm{~g} / \mathrm{d}$ by steers could be regarded as safe. Melamine has recently been found in some dairy cow diets in South Africa at various levels, depending on the amount of the adulterated gluten meal that was included in the dairy concentrates. No reports could be found in the literature on melamine in dairy cow diets and until now, it was generally believed highly unlikely for ingested melamine to be excreted into cow's milk.

A study was done at the Stellenbosch University (South Africa) to test the hypothesis that a pathway exists for the transmission of melamine from feed to milk; the objectives were to determine if and when melamine appeared in the milk and how long after removing melamine from the diet would milk melamine concentrations decline to undetectable levels. The trial protocol was approved by the Stellenbosch University's Animal Ethics Committee.

Cows were housed and cared for according to current ethical norms and they did not experience any discomfort at any stage of the trial. Eight lactating Holstein cows, $218 \pm 9$ (SE) DIM with a daily milk production of $24.6 \pm 1.74(\mathrm{SE}) \mathrm{kg} / \mathrm{d}$ and weighing $638 \pm 10.9$ (SE) $\mathrm{kg}$, were stratified according to milk production and then randomly allocated to 2 groups of 4 cows. Cows were housed individually in $6-\times 4-\mathrm{m}$ pens in a wellventilated, semi-open barn with a cement floor. Each cow had access to a sand-bedded sleeping crate, a feeding trough, and fresh water via a ball valve-controlled water bowl. 
Cows received oat hay ad libitum and $15 \mathrm{~kg} / \mathrm{d}$ of the experimental (MEL) or control (CON) dairy concentrate pellets, which were fed at $0630 \mathrm{~h}(8 \mathrm{~kg} / \mathrm{cow})$ and at $1630 \mathrm{~h}(7 \mathrm{~kg} / \mathrm{cow})$, immediately after the morning and afternoon milkings, respectively. On a DM basis, the concentrate consisted of ground corn $(516 \mathrm{~g} / \mathrm{kg})$, soybean meal $(213 \mathrm{~g} / \mathrm{kg})$, cottonseed meal $(67 \mathrm{~g} / \mathrm{kg})$, corn gluten meal $(69 \mathrm{~g} / \mathrm{kg})$, fish meal $(25 \mathrm{~g} / \mathrm{kg})$, molasses syrup $(50 \mathrm{~g} / \mathrm{kg})$, molasses meal $(40 \mathrm{~g} / \mathrm{kg})$, limestone $(10 \mathrm{~g} / \mathrm{kg})$, salt $(5 \mathrm{~g} / \mathrm{kg})$, monocalcium phosphate $(3 \mathrm{~g} /$ $\mathrm{kg}$ ), and a trace mineral premix $[2 \mathrm{~g} / \mathrm{kg}$; Advit Animal Nutrition SA (Pty) Ltd., Kempton Park, South Africa]. The concentrate had a calculated CP content of $250 \mathrm{~g} /$ $\mathrm{kg}$ of DM and an NDF content of $190 \mathrm{~g} / \mathrm{kg}$ of DM. The MEL and CON pellets were therefore identical in physical composition, except that the CON pellets contained $69 \mathrm{~g} / \mathrm{kg}$ of a locally produced, melamine-free corn gluten meal, whereas the MEL pellets contained the same amount of a Chinese corn gluten meal with 15,117 mg/ $\mathrm{kg}$ of melamine (by liquid chromatography tandem MS analysis, determined in our lab). Because of the sensitivity of this issue and a confidentiality agreement, the supplier of the contaminated corn gluten meal cannot be disclosed. Total mixed rations and dairy concentrates in South Africa would, respectively, not contain more than $50 \mathrm{~g} / \mathrm{kg}$ and $70 \mathrm{~g} / \mathrm{kg}$ of corn gluten meal. In an attempt to ensure that we had the best chance of detecting significant levels of melamine in the milk, it was decided to include the maximum amount of corn gluten meal in the concentrate pellets which, in the end, came to $69 \mathrm{~g} / \mathrm{kg}$. The adulterated corn gluten meal had a CP content of $674 \mathrm{~g} / \mathrm{kg}$ (DM basis), and previous microscopic analysis (C. W. Cruywagen; unpublished data) revealed that it consisted of wheat starch, wheat bran, corn bran, corn gluten feed, corn gluten meal, urea, melamine, and colorants. One tonne of each concentrate diet was manufactured, pelleted, and bagged in 50-kg bags. Analyses of samples taken randomly from 7 bags of each treatment indicated that the CON pellets had a CP content of $251 \mathrm{~g} / \mathrm{kg}$, and that of the MEL pellets was $263 \mathrm{~g} / \mathrm{kg}$. The difference was due to the higher $\mathrm{CP}$ content of the adulterated Chinese corn gluten meal. The analysis also confirmed that the CON pellets contained no detectable melamine (i.e., $<0.001$ $\mathrm{mg} / \mathrm{kg}$ ), whereas the MEL pellets contained 1,142 mg/ $\mathrm{kg}$ of melamine, which compared well with the calculated value of $1,043 \mathrm{mg} / \mathrm{kg}$. Ingestion of $15 \mathrm{~kg}$ of the MEL pellets would thus result in a melamine intake of 17.1 g/d per cow. Calculations based on the work of Clark (1966) and Newton and Utley (1978) would suggest that intake of 0.13 to $0.16 \mathrm{~g} / \mathrm{kg}$ of live weight should not have a detrimental effect on the health of ruminant animals. On this basis, a $650-\mathrm{kg}$ lactating dairy cow should be able to ingest 85 to $100 \mathrm{~g} / \mathrm{d}$ of melamine without apparent ill effects. In the current trial (intake of $17 \mathrm{~g} / \mathrm{d}$ of melamine per cow), we therefore assumed that cow health would not be compromised.

Before commencement of the trial, milk of all the cows was tested and no melamine was detected in any of the samples. At the onset of the trial, all cows received the melamine-free CON pellets for $2 \mathrm{~d}$ to ensure that they ate the feed and that the milk tested free of melamine. From the third day, the 4 cows in the experimental group received the MEL dairy pellets. Cows continued to receive the respective treatment diets for $8 \mathrm{~d}$ to determine the asymptote milk melamine level. The MEL group was then changed back to the control diet for another $5 \mathrm{~d}$. Refusals were weighed back daily before the a.m. feeding, but refusals consisted of oat hay alone, as all the cows ate all their concentrate pellets each day. Cows were milked twice daily at 0500 and $1500 \mathrm{~h}$, and milk yield was recorded individually at each milking throughout the trial. Because of the number of samples and the high cost of analysis, milk was sampled only once a day, during the p.m. milking. Milk samples were split into subsamples to be stored at $-18^{\circ} \mathrm{C}$ or preserved with potassium dichromate until analyzed. The frozen samples were analyzed for melamine, and the dichromate-preserved samples were tested for milk protein, fat, lactose, and MUN content with the aid of a MilkoScan FT 6000 (Foss, Hillerød, Denmark).

For the duration of the trial, milk from cows on the MEL diet was collected separately and discarded by washing it down the drain. Any milk that could possibly be contaminated with melamine was therefore never mixed with the other milk.

On the last day of the MEL treatment, spot urine samples were taken from all the cows. The urine samples were stored at $-18^{\circ} \mathrm{C}$ until analyzed for melamine. After the trial had ended and milk from all the cows contained no detectable levels of melamine, the cows were reinstated into the Stellenbosch University's dairy herd.

For melamine analysis, an adapted method of Shai et al. (2008) was used. Feed samples were prepared by grinding through a 1-mm screen, and 1-g quantities were extracted with $10 \mathrm{~mL}$ of acetonitrile (50\%). Milk and urine samples were diluted 1:1 in $0.2 \mathrm{M}$ perchloric acid and centrifuged at 4,500 $\times g$ for 5 min. Cation-exchange solid-phase extraction cartridges (Phenomenex Strata SCX; $55 \mu \mathrm{m}, 70$ A, $500 \mathrm{mg} / 3 \mathrm{~mL}$, supplied by Separations, Randburg, South Africa) were conditioned with $6 \mathrm{~mL}$ of methanol, followed by $6 \mathrm{~mL}$ of water. The supernatants of the milk samples $(0.5 \mathrm{~mL})$ were loaded onto the cartridges together with $100 \mu \mathrm{L}$ of a $0.5 \mathrm{mg} / \mathrm{L}$ stable isotope-labeled melamine $\left({ }^{13} \mathrm{C}_{3} \mathrm{H}_{6}{ }^{15} \mathrm{~N}_{3}\right)$ internal standard solution (Cambridge Isotope Laboratories Inc., Andover, MA). Thus, $0.05 \mu \mathrm{g}$ of labeled melamine 


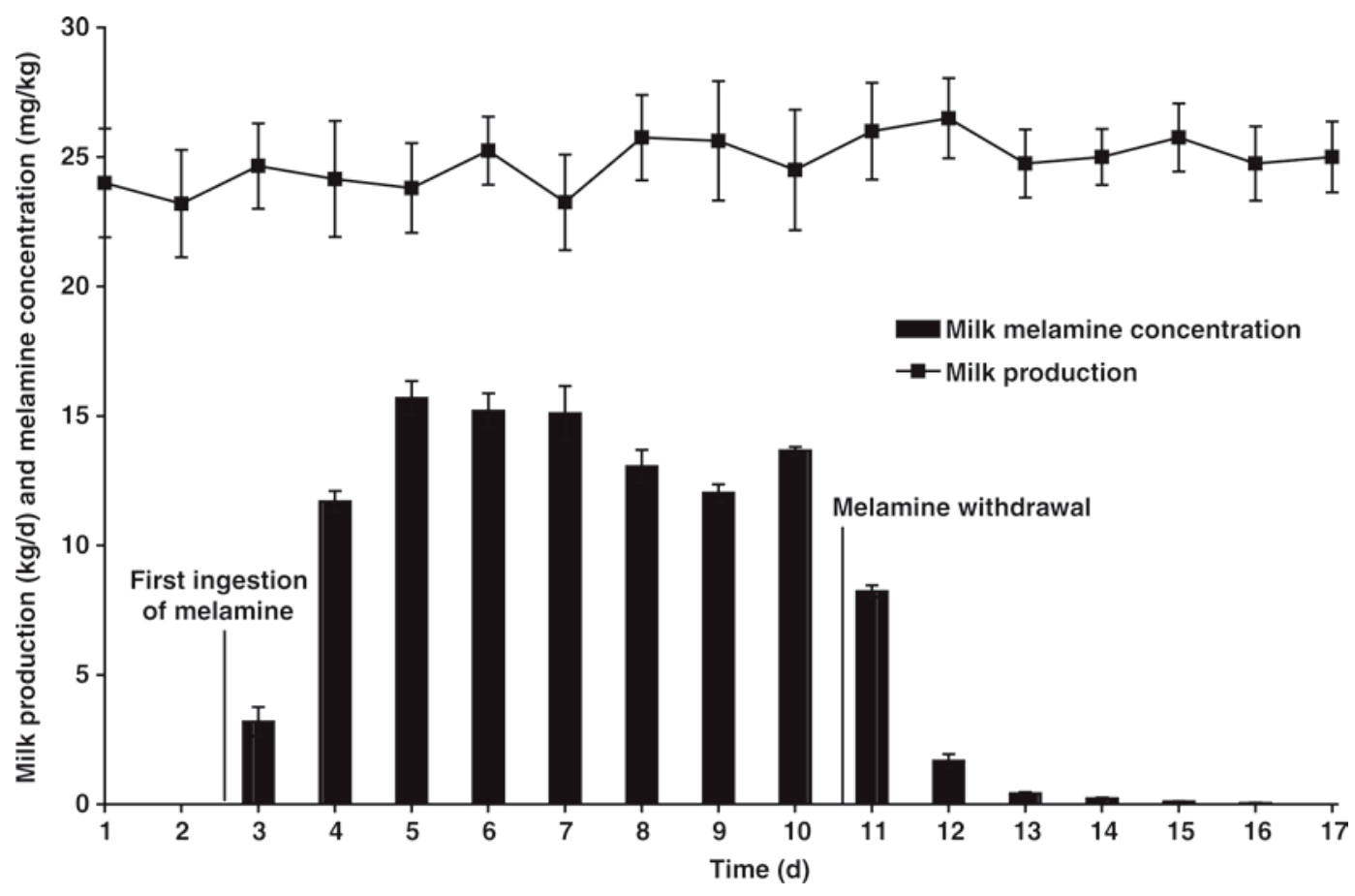

Figure 1. Milk production and melamine concentration of milk from cows that ingested $15 \mathrm{~kg} / \mathrm{d}$ of a pelleted dairy concentrate that contained $1,142 \mathrm{mg} / \mathrm{kg}$ of melamine. First ingestion of melamine was $8 \mathrm{~h}$ before the afternoon milking on $\mathrm{d} 3$ of the trial. Daily melamine intake was $17.1 \mathrm{~g} /$ cow.

was loaded onto each cartridge. The cartridges were washed with $0.1 \mathrm{~N} \mathrm{HCl}(6 \mathrm{~mL})$ followed by methanol $(6 \mathrm{~mL})$ and aspirated under vacuum for $1 \mathrm{~min}$; the melamine was then eluted with $6 \mathrm{~mL}$ of ammonium hydroxide:methanol:dichloromethane (1:5:5) into a clean tube. The extracts were dried under a stream of nitrogen and resuspended in $1 \mathrm{~mL}$ of acetonitrile (50\%). Samples were analyzed by liquid chromatography tandem MS on a Waters API Quattro Micro triple quadrupole mass spectrometer coupled to a Waters 2690 HPLC (Waters Corp., Milford, MA). The limit of detection of the method is $0.001 \mathrm{mg} / \mathrm{kg}$ for feed samples and $0.005 \mathrm{mg} /$ $\mathrm{kg}$ for milk and urine samples. The average recovery for fortified milk was $102 \%$ spiked at levels of $0.5 \mathrm{mg} /$ $\mathrm{kg}$ and $5 \mathrm{mg} / \mathrm{kg}$. The internal standard was used to correct for dissimilarities in recovery rates at different concentrations.

Milk composition data were subjected to a one-way ANOVA using the GLM procedure of SAS (SAS Institute, 1999). Significance was declared at $P<0.05$. Because only the MEL treatment resulted in milk melamine, no statistical analyses were done on melamine data, except for standard error bars that were included in Figure 1 to indicate variation in daily milk production and melamine content over time.

Results (Figure 1) confirm the existence of a pathway of melamine from feed to milk. Milk from the CON treatment never contained detectable melamine, but melamine appeared in milk from cows in the MEL treatment $8 \mathrm{~h}$ after first ingestion of the melaminecontaining diet. Melamine concentration increased rapidly and reached a maximum within $56 \mathrm{~h}$ after first ingestion of the experimental diet. The exact time of first appearance of melamine and the time to reach maximum concentration in milk are still unknown, because in our trial, milk was sampled at 24 -h intervals during the afternoon milkings, which were $8 \mathrm{~h}$ after the morning feeding. In this trial, the melamine excretion efficiency ( $g$ of melamine ingested/g of melamine excreted into milk) was $0.5 \%$ at $8 \mathrm{~h}$ after first ingestion. When the maximum concentration was reached, the excretion efficiency increased to $2.1 \%$. After the maximum melamine concentration had been reached, values fluctuated somewhat over the next $5 \mathrm{~d}$ while cows were on the MEL treatment. This fluctuation was probably related to daily variations in milk production (Figure 1). Afternoon milk yields showed the same fluctuation patterns as total milk and it was thus accepted that calculations based on the analysis of afternoon milk only were probably representative of the pattern of total melamine concentrations in milk. The mean melamine excretion efficiency during this period ranged from 1.7 to $2.1 \%$. When cows were switched back to the CON pellets, the concentration of milk melamine 
Table 1. Milk production and composition of cows in the melamine trial

\begin{tabular}{lrrrr}
\hline & \multicolumn{2}{c}{ Treatment $^{1}$} & & \\
\cline { 2 - 3 } Item & MEL & CON & SEM & P-value \\
\hline Daily milk yield $(\mathrm{kg})$ & 24.9 & 24.3 & 1.22 & 0.770 \\
Milk fat $(\mathrm{g} / \mathrm{kg})$ & 32.6 & 33.8 & 4.12 & 0.845 \\
Protein $(\mathrm{g} / \mathrm{kg})$ & 34.7 & 36.3 & 2.60 & 0.675 \\
Lactose $(\mathrm{g} / \mathrm{kg})$ & 47.6 & 47.1 & 1.42 & 0.824 \\
Total solids $(\mathrm{g} / \mathrm{kg})$ & 118.7 & 124.4 & 5.92 & 0.518 \\
MUN $(\mathrm{mg} / 100 \mathrm{~mL})$ & 16.8 & 17.3 & 0.62 & 0.583 \\
\hline
\end{tabular}

${ }^{1} \mathrm{MEL}=$ melamine treatment: cows received oat hay ad libitum and $15 \mathrm{~kg} / \mathrm{d}$ of a concentrate pellet containing $1,142 \mathrm{mg} / \mathrm{kg}$ melamine; $\mathrm{CON}=$ control diet: cows received oat hay ad libitum and $15 \mathrm{~kg} / \mathrm{d}$ of a melamine-free concentrate pellet.

responded rapidly and dropped $39 \%$ within $8 \mathrm{~h}$ and $85 \%$ within $32 \mathrm{~h}$. After that, milk melamine levels declined and melamine could not be detected in milk 152 $\mathrm{h}$ after changing back to CON pellets. It is speculated that dietary melamine concentration would have an effect on melamine excretion efficiency as well as on the time for melamine to disappear from the milk once a contaminated diet had been removed.

The implications of our results are important to the dairy industry. The US Food and Drug Administration recently announced that levels of melamine $<2.5 \mathrm{mg} / \mathrm{kg}$ in foods other than infant formula do not raise public health concerns (CNN, 2008). They set the maximum level for infant formula at $1 \mathrm{mg} / \mathrm{kg}$. If a dairy cow concentrate contained $40 \mathrm{mg} / \mathrm{kg}$ of melamine and it was fed at a level of $12 \mathrm{~kg} / \mathrm{d}$ to cows with a similar milk production as those in the current study $(25 \mathrm{~kg} / \mathrm{d})$, then our results would suggest an expected milk melamine concentration of $0.4 \mathrm{mg} / \mathrm{kg}$. This might be seen as a "safe" level, but when such milk is converted to milk powder, the melamine level would be concentrated approximately 8 -fold to $3.2 \mathrm{mg} / \mathrm{kg}$, which is above the accepted level, especially when the resultant powder is to be used in infant formula.

Milk composition was not affected by treatment (Table 1). No literature could be found on the ruminal degradability of melamine, but it is expected that melamine would be degraded to some extent. The question was therefore asked whether dietary melamine would affect MUN. It is clear from Table 1 that MUN content was not affected by melamine ingestion.

Excretion via milk accounted for only $2 \%$ of the ingested melamine. The absorption rate of melamine from the digestive tract is still unknown, but documented evidence of kidney damage and melamine crystalluria (Clark, 1966) would suggest that the major excretion pathway is via urine. According to the report of an expert meeting of the World Health Organization (2008b), melamine and cyanuric acid are rapidly absorbed in monogastric animals and excreted unmetabolized in the urine. It is postulated that the same happens in ruminants, as we could find no documented evidence of significant melamine degradation in the rumen. Melamine can also react with cyanuric acid on a 1:1 basis to form spoke-like melamine cyanurate crystals from aqueous solutions. These crystals have been implicated as a causative toxicity agent in the Chinese protein export contamination and the 2007 pet food recall (He et al., 2008). In the current trial, analyses of urine samples taken from all the cows on the last day of the MEL treatment indicated that urine of cows in the MEL treatment contained $452.3 \pm 21.3(\mathrm{SE}) \mathrm{mg} / \mathrm{kg}$ of melamine, whereas no melamine was detected in the urine of cows in the CON treatment. The concentration of melamine in the urine of cows fed MEL supports the hypothesis that urine is the major route of melamine excretion in lactating dairy cows.

We concluded that a pathway exists for the transmission of melamine from feed to milk and the kinetics suggest that milk melamine concentration responds rapidly to the introduction of melamine-contaminated feed. However, despite a rapid initial decline in melamine concentration upon removing melamine from the feed, it can take $6 \mathrm{~d}$ or longer before the milk is completely free of melamine again. This is probably related to the passage rate of melamine-containing feed from the rumen. Dietary melamine concentration and feeding behavior of cows would likely affect milk melamine concentration and excretion efficiency. Apparent complete clearance of melamine from milk would depend on the sensitivity of analytical methods and would probably also be affected by dietary melamine concentration. Results from the current trial have implications for the dairy industry because, until now, any melamine found in milk and milk products was attributed only to the deliberate external addition of melamine to these products and not to adulterated ingredients in animal feeds.

\section{ACKNOWLEDGMENTS}

The authors express gratitude to Tanqua Feeds (Riviersonderend, South Africa) for sponsoring the feed and mixing the concentrate diets according to our specifications, and Ivan Stevens (farm manager), Sam Pietersen, and James Williams, all at the Welgevallen Experimental Farm of the Stellenbosch University, for caring for the animals. The Hennie Steenberg Trust Fund is acknowledged for financial assistance.

\section{REFERENCES}

AllAboutFeed. 2009. Animal feed and animal nutrition news. 296,000 hit by Chinese milk poisoning. http://www.allaboutfeed.net/ 
home/id102-79205/296000_hit_by_chinese_milk_poisoning.html Accessed Jan. 15, 2009.

AOAC. 2000. Official Methods of Analysis. 17th ed. Assoc. Off. Anal. Chem. Int., Gaithersburg, MD.

Clark, R. 1966. Melamine crystalluria in sheep. J. S. Afr. Vet. Med. Assoc. 37:349-351.

CNN. 2008. FDA sets "safe" levels for melamine in baby formula. http://www.cnn.com/2008/US/11/28/infant.formula.melamine/ index.html Accessed Dec. 18, 2008.

He, L., Y. Liu, M. Lin, J. Awika, D. R. Ledoux, H. Li, and A. Mustapha. 2008. A new approach to measure melamine, cyanuric acid, and melamine cyanurate using surface enhanced Raman spectroscopy coupled with gold nanosubstrates. Sens. Instrum. Food Qual. 2:66-71.

MacKenzie, H. I. 1966. Melamine for sheep. J. S. Afr. Vet. Med. Assoc. 37:153-157.

Merck. 2001. Entry 5834, page 1038 in The Merck Index. 13th ed. Merck Research Laboratories, Whitehouse Station, NJ.
Newton, G. L., and P. R. Utley. 1978. Melamine as a dietary nitrogen source for ruminants. J. Anim. Sci. 47:1338-1344.

SAS Institute. 1999. SAS/STAT User's Guide, Version 8.2. SAS Inst. Inc., Cary, NC.

Shai, J., C. Mallet, M. Young, J. Li, Y. Meng, and C. Qi. 2008. Application note: Rapid specific analysis of melamine contamination in infant formula and liquid milk by UPLC/MS/MS. Waters Corporation, Milford, MA.

World Health Organization. 2008a. Melamine and cyanuric acid Toxicity, preliminary risk assessment and guidance on levels in food. 25 September 2008; Updated 30 October 2008. http://www. who.int/foodsafety/fs_management/Melamine.pdf Accessed Dec. 18, 2008.

World Health Organization. 2008b. Expert meeting toreview toxicological aspects of melamine and cyanuric acid. In collaboration with FAO, supported by Health Canada Ottawa Canada. http://www.who. int/foodsafety/fs_management/conclusions_recommendations.pdf Accessed Feb. 24, 2009. 